\section{TWO CASES OF DEFORMITY OF THE HAND RELIEVED BY OPERATION. ${ }^{1}$}

By NOBLE SMITH, F.R C.S. EDIN

gckgEOY TO THE CITY ORTHOPADIC HOSPITAL, AND SURGEON TO THE ALL SAINTS CHILDREN'S HOSPI'CAI.

CASE 1.-1 woman, age 1 forty-five years, was admitted to the City O.thoprelic H spital on July 13:b, 1896. The patient give the following history of her cass:-Ten years previou:ly, while alighting from a tram-car, she was thrown off under a fassing vehicle and her left hand was crushed by one of the wheels. She was taken to the Royal Free Hospital, where the hand was dressed, and where a few weeks later it was fuund nezessary to amputate the end of the second fingar. Two years later, finding that her hand was becoming contracted and was very painful, she went to the Mildmay Hospital, where the end of the little finger was amputated. During the next few years she underwent many operations, apparently for the removal of diseased bone, but the hand gradually contracted more and more, the pain became very severe and the hand absolutely useless, so that amputation was proposed, at one of the Londen hospitals, as the only effective remedy. The patient then came to the City Ocinopedic Hospital. When admitted she was in an emaciated condition, and was suffering extreme pain in the affected part. There was a trophic ulcer on the back of the hand discharging freely. The hand was so tightly clenched, that it was impossible to separate the mutilated thumb from the fingers or the fingers from the palm of the hand, and the skin had a "glossy" appearance (Fig. 1). On July 16th I

FIG. 1.

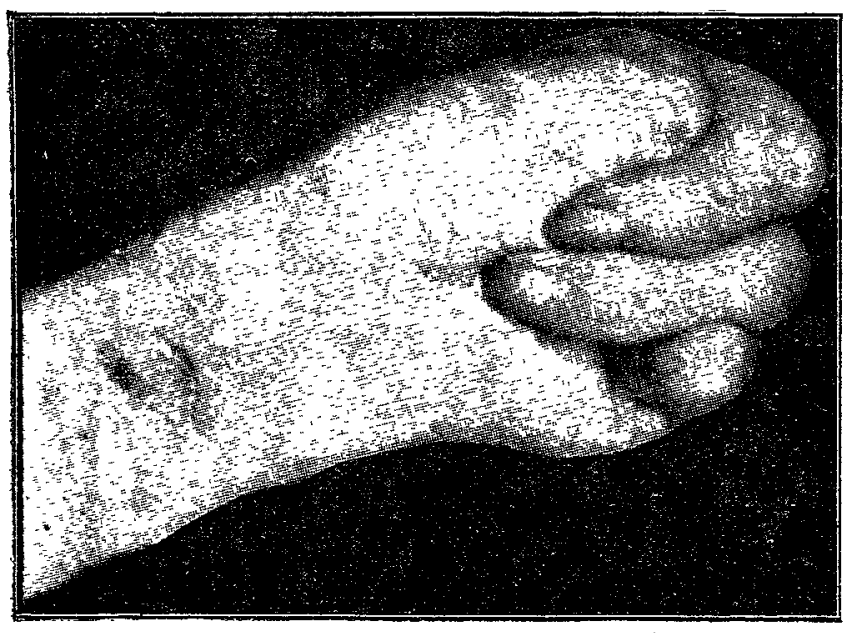

The hand before operation.

performed the following operation. A transverse incision was made across the front of the wrist and the tendons of the palmaris longus and flexor sublimis muscles and the ulnar and median nerves were divided. The median nerve was much enlarged. After the tendons were divided it was possible to extend the fingers into a fairly good position, but bearing in mind the extreme sensibility of the nerves supplying the hand, as evinced by the great pain and the "glossy" condition of the skin, I feared that tenotomy alone would not remove the suffering, and realising that, unless this were relieved, the only other resource was amputation, I felt emboldened to divide the nerves in spite of the possibility of serious interruption to the nutrition of the hand by cutting off so large an extent of nerve. supply. The result was very satisfactory. The patient was immediately relieved from much of her pain and in a few days was quite free from suffering, the wound healing up rapidly. A few weeks later I noted that the patient was free from pain; the trophic ulcer was healing; she could move the fingers slightly and could grasp a spoon or other article between her stump of the thumb and her fingers (Fig. 2). Since that period the ulcer has healed up entirely, and although there is considerable stiffness in the fingers, the fact of the patient being able to grasp renders the hand a

1 These cases were shown and described at the meeting of the Iledical Society of London on Feb, 8th, 1897 very usefnl one. On $J$ เn. 11th I diviced a tense band of fascia which passer fro $n$ the bas a of the thumb towards the base of the middle finge; , because this rart was contracting.

FIa. 2.

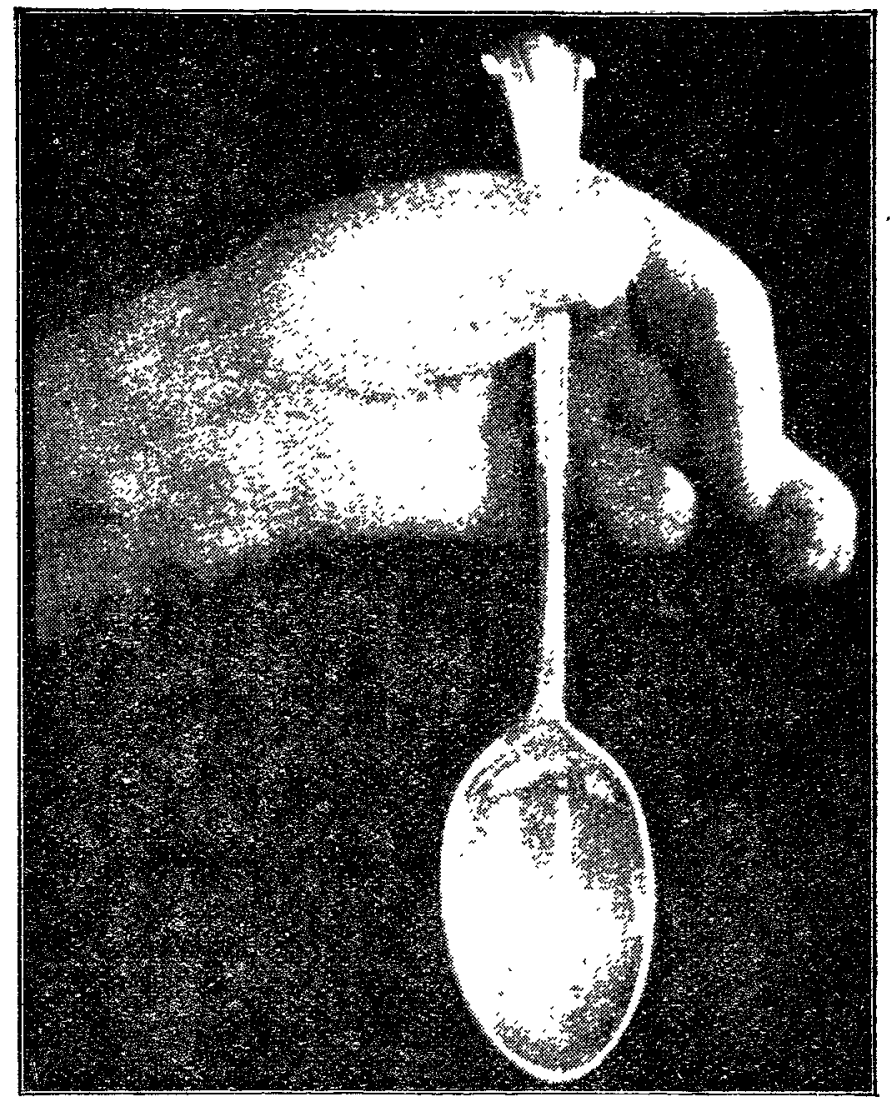

The same three months after operation.

I also broke down some of the stinf finger-joints. As regards numbness caused $t y$ the neurotomy, the patiert made no

FIG. 3.

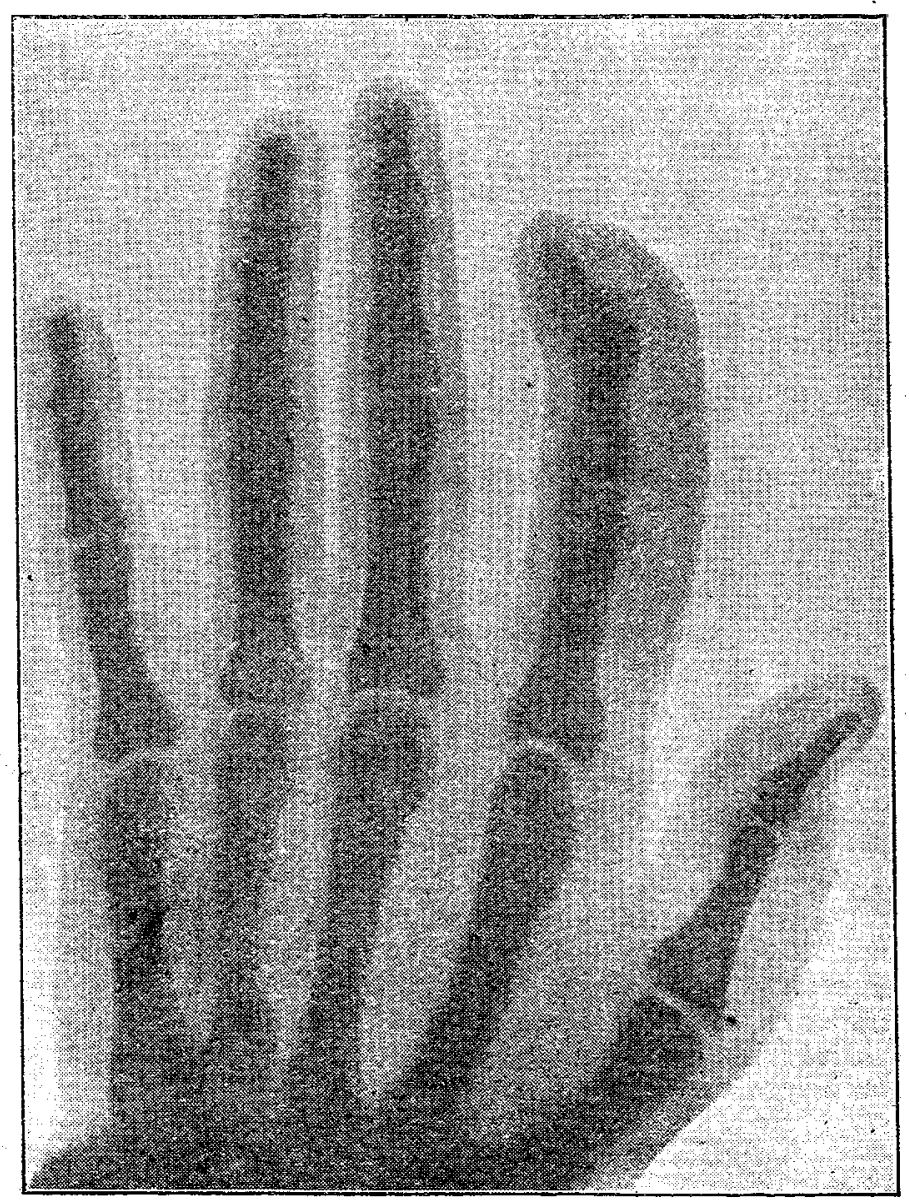

Skiagraph of hand before operation.

complaint except upon inquiry about a fortnight after the operation. The loss of the pain was such a relief to her that the numbness was doubtless felt as a benefit. The progress G 2 
was so satisfactory that it was not until November-that is, Cour months after operation-that I tested the sensation of the skin, when $I$ found it very good. There was a small area of numbness in the palm at the base of the middle and ring fingers, but not elsewhere, and the two points of a pair of scissors could be separately detected in the other parts.

CASE 2.-A woman, aged twenty-three years, gave the following history of her case : At the age of fifteen months she fell down some steps and when picked up it was found that the thumb and index finger of her right hand had " doubled up." Ten years later, finding that the finger was becoming crooked and abnormally large, the patient was taken to a hospital, where it was said that amputation was the only remedy. The patient did not obtain any other advice until she came to the City Orthopædic Hospital a year ago as an out-patient. The thumb and index finger were then found to be much enlarged and the distal end of the index finger was turned in the ulnar

FIG. 4.

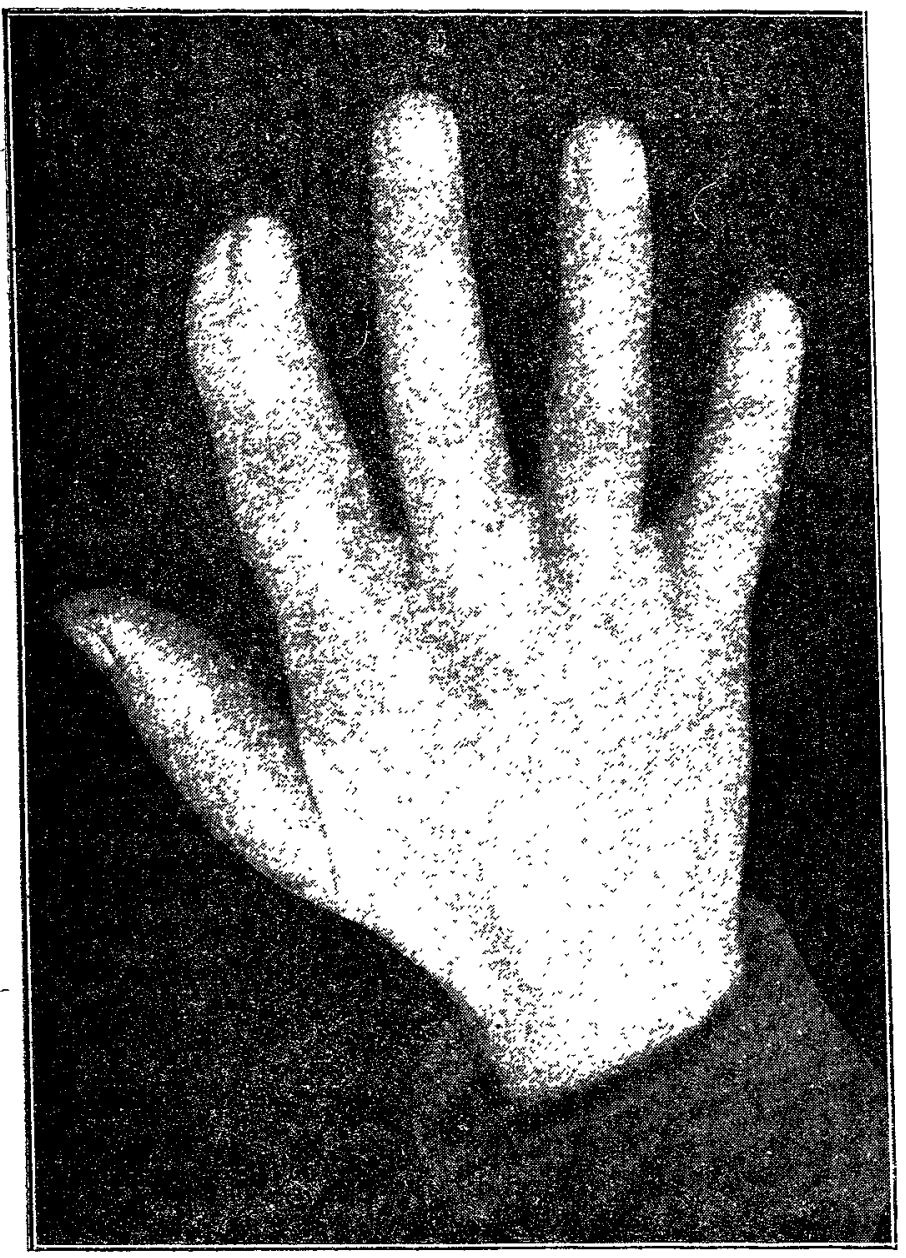

From a photograph of hand taken January, 1897.

direction. The patient was a waitress and she became unable to do her work properly, especially as she could not cut up bread and butter, which was one of her duties. The exact nature of the enlargement was not clear, but it so closely simulated the appearance of congenital hyper. trophy that I thought the bones were probably enlarged and that there was an excess of fatty tissue. Mr. Sydney Rowland took a skiagrapn of the hand (Fig. 3) which showed that the bones were normal as to size and that the enlargement was entirely due to soft tissue. The Roentgen rays also showed. the exact shape of the last phalangeal joint of the ind $\epsilon x$ finger, the deformity being produced by irregularity in the shape of: both of the bones forming that joint. I cperated at first for the lipoma, which I found diffused between the tendons ir: all directions. I was able to pull out long threads of the fatty nodules which probably come under the denomination of lipoma arborescens of T. Muller. Billroth refers to the analogy between this form of lipoma and the proliferation of fat in the processes of the peritoneum, of the large intestine (the appendices epiploice), and other serous membranes. This variety, says Billroth, is extraordinarily rare. Bland Sutton states that diffuse lipomata do not admit of removal, and certainly in this case to have removed all the redundant fat would have been a tedious procedure, but the result of removing a great portion of it was very satis factory. The immediate diminution in size enabled the patient to use her hand with much less inconvenience, and n the course of some weeks the affected part became stil smaller. It was now found that the bend at the end of the index finger was a source of great inconvenience, as it would catch the middle finger. I therefore cut down upon the radial side of the finger and cut the second phalanx transversely with bone forceps nearly to the ulnar border. I then forcibly broke the remaining piece of bone bringing the finger into a straight line. There remains a very slight inclination of the terminal phalanx towards the middle finger, but this gives the patient no inconvenience. The skiagraph shows the hand before the operation, and the photcgraph (Fig. 4) depicts its appearance at the present time. The hand is now perfectly useful, but if necessary more of the fatty tissue will be removed by further operation. Queen Anne-street, W.

\section{AN UNUSUAL CASE OF TUBAL ABORTION.}

\section{BY J. BLAND SUTTON, F.R.C.S. ENG,}

SURGEON TO THIE CHEXSEA HOSPITAL FOR WOMEN AND ASSISTAXT SURGEON TO THE MIDDLESEX HOSPITALI

THE following is a record of the most curious case of tubal abortion which has come under my notice. In addition to its novelty there are several points of clinical interest well wortl consideration, as they demonstrate the fact that under some conditions tubal abortion can be differentiated frcm tuba? rupture by the clinical signs.

A married woman, aged forty-one years, the mother of four children, was last pregnant in May, 1886. From that date she continued regularly to menstruate till June, 1896. In that month and in July, August, and September the usual menstrual period was represented on each occasion merely by a "slight loss." On July 28 th the patient had severe pain. in the lower part of the abdomen lasting three hours. On Aug. 14th a similar attack occurred. On Sept. 15th she was. again in great pain, which lasted five days. The pain diminished in severity but did not wholly subside, and she sought relief at the Chelsea Hospital for Women, where she was examined by Dr. Arthur Giles, who detected a swelling:

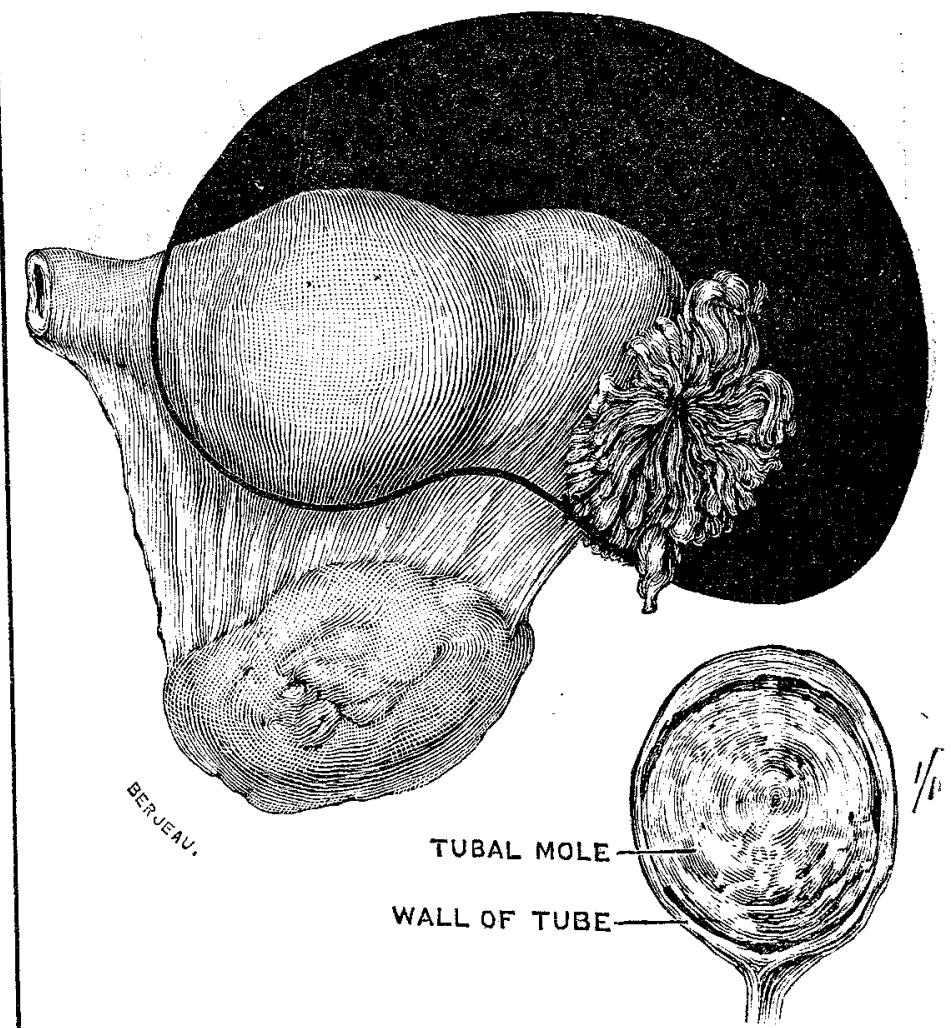

Figure of a gravid tube. The dark outline represents the shape and size of the smallest clot. It also shows the shape of the ampulla of the tube when distended.

in the left half of the pelvis. From the physical signs and the history he regarded the case as "tubal pregnancy and very probably tubal abortion," and sent her into the ward. On examining the patient I found the left half of the pelris occupied by a semi-solid swelling which extended into the 